\section{P5.005 INVESTIGATION OF NEW APPROACH TOWARDS ROAD ENFORCEMENT SYSTEM IN POLAND}

Justyna Wacowska-Slezak*, Aneta Wnuk, Dagmara Jankowska-Karpa. Motor Transport Institute, Warsaw, Poland

\subsection{6/injuryprev-2021-safety.225}

Context Poland is covered by the automatic traffic enforcement system. Since road safety improvement progress in Poland is slow, it was decided to expand this system.

Process In 2019, a methodology was developed to optimize the selection process of recording devices locations, including enforcing the exceeding of speed limits and entering the intersections at red light. By using more technologically advanced recording devices, road network covered by automatic enforcement system has been expanded.

Analysis The available data regarding locations of accidents and collisions was collected. Data was verified and superimposed on country map, broken down into accidents' types. Data on accidents included their severity due to exceeding the speed limit, not maintaining a safe distance between vehicles, non-compliance with traffic lights etc. Spatial and multifactorial analyses were carried out as well. The maps were divided into areas and the degree of risk for each area was assessed. Each area was evaluated with regard to different weights, assigned according to events' severity and type. Methods for determining the intensity of traffic incidents and algorithms for creating ranking lists were developed. Based on that, specific areas were selected for further analyses.

Outcomes Based on the carried out analyses, locations for new recording devices were selected, ranking list of locations and risk maps were developed for all road types.

Learning Outcomes The new approach to the process of locations' selection of the recording devices is easy to implement and will contribute to the optimization of this process and, consequently, to road safety improvement.

\section{P5.006 ROAD SAFETY INFORMATION AND KNOWLEDGE MANAGEMENT MODEL}

Justyna Wacowska-Slezak*. Motor Transport Institute, Warsaw, Poland

10.1136/injuryprev-2021-safety.226

Context Every year there are over 35,000 road accidents in Poland, in which over 3000 people are killed and more than 40,000 are injured. Road accidents constitute a very heavy financial burden, they cost the state over PLN 33 billion a year (more than the state's expenditure on health care, education and higher education together), which accounts for almost 3\% of GDP.

Process The interdisciplinary theoretical basis for the model was formulated. The review of good practices in the development of information systems concerning road safety to identify effective solutions was carried out.

Analysis Numerous analyses were carried out, including an analysis of the main road safety problems in Poland and around the world. It covered the issues related to the need for: scientific research on road safety, collection and arrangement of road safety data, coordination of activities concerning road safety, as well as monitoring of undertaken activities and dissemination of knowledge and good practices in road safety.
Outcomes Road safety information and knowledge management model can provide effective support to good decision making when designing and implementing road safety policies.

Learning Outcomes This model allows to collect, store, process, analyse, and make data, information, and knowledge available in the area of road safety. It constitutes a solid, reliable, and credible source of information for policy makers when developing road safety policies and strategies. This tool can be constantly improved, and data collection can be systematically expanded.

\section{P5.007 ROAD SAFETY ACTIVE EDUCATION METHODS IN THE OPINION OF YOUNG ROAD USERS}

Dagmara Jankowska-Karpa, Justyna Wacowska-Slezak, Aneta Wnuk*. Motor Transport Institute, Warsaw, Poland

\subsection{6/injuryprev-2021-safety.227}

Background Contemporary educational needs require searching for and using more effective and attractive solutions to reach young road users, an example of which is active education AE.

Process Traditional learning methods are based on teacher as a source of knowledge. In AE teacher is the coordinator of students' work, activates them and acts as an advisor or observer. We have conducted projects and studies using road safety $\mathrm{AE}$ (e.g. workshops, demonstrations, problem solving) addressed to youth: Young Explorer University/YEU, Road Safety Education Centre/RSEC, European Road Safety Tunes/ERST, Knights for Road Safety/KROS. During classes youth is motivated to act by being encouraged, inspired, enabled to participate, which contribute to a sense of success, joy of effort, showing abilities, gaining recognition, and enabling to reflect on own and others' behaviour.

Analysis Our educational goal is among others to create among students a sense of independence and responsibility for themselves and others. The results of qualitative and quantitative studies show that such classes, in the opinion of youth are more attractive and effective than traditional, e.g. overall grade of class: very good and good: YEU (89\%), RSEC (81\%), ERST (89\%).

Outcomes AE will not cure all road safety problems of youth. However it is important to effectively transfer knowledge, teach skills and attitudes, but also to make the classes more attractive for students.

Learning Outcomes Pedagogy is a dynamic discipline with various methods as AE. It requires teachers to constantly adapt to new needs and expectations as well as to undergo professional development.

\section{P5.008 SAFETY ASPECTS OF E-BIKES}

Ma (fh) Ernestine Mayer* , Klaus Robatsch. Austrian Road Safety Board, Vienna, Austria

\subsection{6/injuryprev-2021-safety.228}

Background E-bikes have become a popular means of transport in everyday and leisure traffic, especially for older people. Figures show a rapid increase in the number of e-bikes on the market: In 2018 more than 150.000 e-bikes were sold 